\title{
Fuego festivo, humo sagrado: Las luminarias de San Antón en Tierra de Pinares (Ávila)
}

\author{
Festive Flames, Sacred Smoke: \\ Ávila's St Anthony Bonfires
}

\author{
María Tausiet \\ Centro de Ciencias Humanas y Sociales. CSIC. Madrid
}

\section{RESUMEN}

La festividad de San Antonio Abad, más conocido como San Antón, continúa celebrándose en muchas localidades españolas cada 17 de enero. En pleno período invernal, tradicionalmente caracterizado por el reposo de los trabajos agrícolas, se lleva a cabo un ritual de purificación y renovación de la naturaleza a través del fuego (hogueras), cuyos antecedentes se remontan a la religión romana arcaica. La localidad de San Bartolomé de Pinares (Ávila) constituye un buen ejemplo de la pervivencia de esta fiesta que no sólo se ha conservado, sino que se ha revitalizado en los últimos años. Gracias a los testimonios de varios informantes entrevistados en 2008 puede entenderse mejor tanto el sentido primitivo de la fiesta ("librar al pueblo de las fuerzas del mal") como su progresiva secularización.

Palabras clave: San Antonio Abad, San Antonio de Padua, Rituales de purificación, Fuego festivo, Luminarias, Fiestas tradicionales.

\section{SUMMARY}

The feast-day of Anthony the Abbot, better known simply as St Anthony, is still celebrated in many Spanish towns and villages on 17 January every year. In the depths of winter, traditionally a period of rest from agricultural labour, people light bonfires in a renewal and purification ritual whose origins lie in the religious practices of Ancient Rome. In the village of San Bartolomé de Pinares, in the province of Ávila, the St Anthony celebrations have not only survived, but have seen a resurgence of interest in recent years. Information gathered from interviews carried out in 2008 gives greater insight into the primitive aspects of the feast-day ("setting the village free from the forces of evil") as well as into its gradual secularisation.

Key words: St. Anthony the Abbot, St Anthony of Padua, Purification Rituals, Festive Flames, Bonfires, Traditional Feast-Days. 
Il fuoco come convertitore della vita in morte e nello stesso tempo della morte in vita, dunque simbolo dell'una e dell'altra ${ }^{1}$.

El fuego - fuente de luz y calor, pero también de destrucción; símbolo dual por antonomasia, capaz de reunir los polos contrarios del bien y el mal- ha protagonizado desde tiempos inmemoriales todo tipo de ceremonias y rituales. En el ámbito judeo-cristiano, la naturaleza ambivalente del fuego se asoció desde el principio tanto a la sabiduría y al amor divinos, a menudo representados en forma de llama incandescente, como a su justicia implacable: no en vano el fuego se consideró instrumento privilegiado de castigo, en este mundo y en el más allá, por los pecados cometidos contra la ley divina. En su doble faceta, creadora y devastadora, el fuego ha sido y sigue siendo, todavía hoy, el centro de muchas fiestas en todo el área euromediterránea. Aunque se trata de fiestas religiosas, enmarcadas en el calendario litúrgico cristiano, gran parte de su significado y su función original entronca con rituales profanos íntimamente relacionados con el paso de las estaciones y las labores agrícolas. (Bayard 1973; González Alcantud y Buxó Rey 1997).

Un buen ejemplo de ello lo constituyen las fiestas en honor a San Antonio Abad, más conocido como San Antón, que se han celebrado y continúan celebrándose a lo largo de toda la geografía española cada 17 de enero, en conmemoración del fallecimiento del santo ${ }^{2}$. Las hogueras encendidas la víspera de la festividad religiosa desempeñan un papel fundamental, pese a no gozar de la fama de las dedicadas a otros santos hoy en día más populares, como San Juan (24 junio) o San José (19 marzo). Aun teniendo en cuenta el declive general experimentado por la fiesta de San Antón desde la década de los setenta, por las transformaciones económicas y sociales ligadas a la industralización y el consiguiente éxodo rural, los lugares que han mantenido la tradición en España son aún muy numerosos ${ }^{3}$. Entre ellos, merece la pena destacar la localidad de San Bartolomé de Pinares (Ávila), donde la fiesta no sólo se ha conservado, sino que incluso se ha revitalizado en los últimos años por razones que se explicarán más adelante.

\footnotetext{
${ }^{1}$ Buttitta (2002: 143).

${ }^{2}$ Véanse Hoyos (1957); Martínez González (1980); Alonso Ponga (1981); Lera de Isla (1982); Fernán Chamón (1983); Elías Pastor (1985); Buendía López (1987); Anta Félez (1997); Rúa Aller (2009), y Velasco Má1lo (2009).

${ }^{3}$ Una lista actualizada de las localidades españolas en que sigue celebrándose la fiesta de San Antón todavía hoy, acompañada de una interesante tabla, así como de comentarios sobre las diferentes manifestaciones festivas, puede verse en Velasco Maíllo (2009: 254-261). Véanse asimismo (Luis 1993; Sánchez Gómez 1995 y García Rodero 1992).
} 


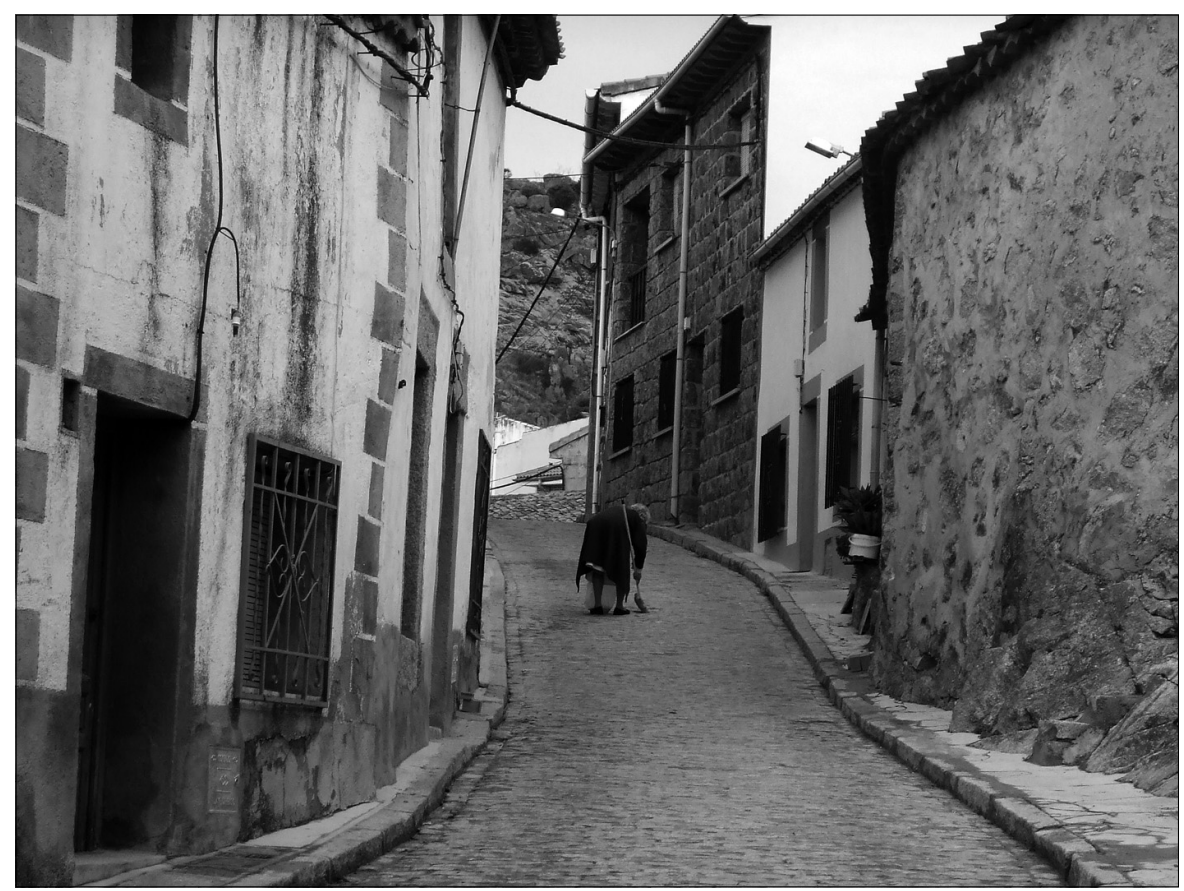

Figura 1. San Bartolomé de Pinares. Calle de la Virgen.

El interés antropológico de lo que se conoce popularmente como la fiesta de las "luminarias" (nombre dado en dicha localidad a las fogatas encendidas en honor a San Antón) estriba no tanto en su carácter excepcional como en su continuidad y en su evolución ${ }^{4}$. Las sucesivas transformaciones de la fiesta ejemplifican de manera significativa el decisivo cambio en la mentalidad y las costumbres experimentado en las últimas generaciones. Buena parte de este trabajo se basa en la memoria de varios testigos, a través de las informaciones que, generosamente, se prestaron a comunicarme en varias series de entrevistas realizadas en febrero de 2008. Dependiendo de su edad, los informantes, bien fueron partícipes de la fiesta a lo largo de muchos años, bien continúan siéndolo en la actualidad. La mayoría de los entrevistados se refirieron no sólo al contenido de la fiesta, sino también a su vivencia personal de ésta y al significado que tenía para cada uno de ellos. Los más ancianos insistían en los cambios acaecidos en las últimas décadas, diferenciando la fiesta de antes y la de ahora. El énfasis de cada informante en unos

${ }^{4}$ Según el "Libro Guinness de los Récords", la hoguera más grande del mundo —en torno a veinte metros de altura- se enciende cada año en la víspera de San Antón en la localidad valenciana de Canals (Luis 1993: 790). 
u otros elementos (como las devociones en honor a San Antón, el humo asfixiante, o el salto a caballo por encima de las hogueras la víspera del día 17) refleja la amplia diversidad de aproximaciones al acontecimiento festivo. El hecho de que los más jóvenes desconozcan el sentido de la mayoría de los actos religiosos revela asimismo su progresiva e imparable secularización.

\section{BREVE SECUENCIA RITUAL}

Antes de analizar los posibles significados de la fiesta, se hace necesaria una rápida exposición, en orden cronológico, de su estructura ritual. Los actos festivos propiamente dichos se concentran en la víspera y en el día de San Antón, pero varias jornadas antes (desde hace algunos años, el sábado anterior a la festividad) tiene lugar la recogida de ramos que servirán para alimentar las hogueras o luminarias. Aunque la localidad, como su propio nombre indica, está situada en "tierra de pinares", habiendo sido éstos muy abundantes hasta el siglo XIX, hoy en día las especies utilizadas principalmente para leña son: piorno, retama negra, tomillo y jara. Se trata de ramos verdes, algunos de ellos olorosos, que provocarán un humo abundante y efectista, aromático y multicolor (marrón, amarillo, blanco, gris, etc.) que, a modo de sahumerio de proporciones gigantescas, invadirá las calles del pueblo en honor al santo. La recolección de los ramos se hace de forma comunitaria y señala, de algún modo, el comienzo de la fiesta ya que, una vez terminada la faena, los participantes lo celebran con una parrillada colectiva en el campo. Actualmente los ramos (mucho más abundantes que en el pasado) se trasladan en grandes camiones. Antiguamente, cada familia aportaba lo que podía (normalmente cinco o seis gavillas) a lomos de caballerías o a las espaldas de quienes recogían los ramos.

El día 16 de enero, hacia las siete y media de la tarde, se celebran en la iglesia mayor las vísperas en honor de San Antón. A continuación, comienzan a encenderse las luminarias, empezando por la del mayordomo o persona encargada de organizar la fiesta ese año. Hacia las nueve de la noche, cuando ya todas las luminarias están ardiendo, repican las campanas de la iglesia y un grupo de jinetes (la mayoría a lomos de caballos; los menos, de mulos y burros) aguarda la bendición de sus caballerías bajo el balcón de la casa sacerdotal. Una vez que el sacerdote ha bendecido a los animales y los ha rociado con un hisopo de agua bendita, el mayordomo invita a los jinetes a tomar pastas y vino de la tierra. A continuación, precedidos por varios músicos encargados de tocar la dulzaina (o gaita) y el tambor, los jinetes dan una vuelta por todo el pueblo de una a otra luminarias.

\footnotetext{
${ }^{5}$ Sobre este tipo de ritual, véanse Castellanos (1848: 19-20) y Cruces Villalobos (1994: 49-70).
} 
Durante el paseo, el mayordomo, seguido de sus dos ayudantes o jurados, porta una vara con un lazo rojo en la que está representado el santo. Antes de que llegue la comitiva a cada hoguera, los encargados de mantenerla humedecen los ramos o echan ramos verdes para producir el máximo humo posible, lo que produce una auténtica nube artificial en todo el pueblo que convierte el aire en irrespirable. Una vez terminado el recorrido en el mismo lugar donde se inició, comienza la parte más espectacular de la fiesta: los saltos a través del fuego a lomos de las cabalgaduras, que se prolongan hasta bien entrada la noche y que cada vez atraen a un número mayor de participantes y curiosos. Cuando los jinetes se retiran, vecinos, amigos y familiares se reúnen en torno a las luminarias para bailar al calor de la lumbre y asar su cena (chuletas, chorizo, morcillas, panceta) en las brasas.

A primera hora de la mañana siguiente, vuelven a encenderse las luminarias con la intención de ahumar al santo a su paso por las calles de la localidad. San Antón sigue estando representado en la vara que porta el mayordomo a lomos de su caballo, ahora engalanado con cintas y flores. Aparte de los dos jurados, también a lomos de sendos caballos adornados, en esta ocasión tan solo le acompañan los músicos. Al pasar por las casas, los vecinos —en su mayoría mujeres ancianas - salen a "besar el santo" (es decir, la parte superior de la llamada "vara del santo") y a entregarle un donativo que antiguamente solía consistir en una o varias patas - o pies- de cerdo. El sentido original del donativo era sufragar comunitariamente los gastos de la fiesta, pero hoy en día se ha quedado reducido a una cantidad de dinero simbólica. Para algunos vecinos, el amanecer del día 17 sigue siendo considerado todavía hoy la parte más importante de la fiesta. Son quienes, al escuchar el toque del tamboril, anunciando la llegada de la escueta comitiva, se apresuran a gritar: “Que viene, que viene!”, y echan más ramos a la luminaria, apagando a continuación las llamas con agua para, de este modo, provocar una densa humareda. Tras recorrer todas las luminarias del pueblo, el séquito se dirige a la iglesia, donde se celebra una misa dedicada a San Antón, cuya homilía dedica cada año el sacerdote a recordar la vida y milagros del santo. A la salida de la iglesia tiene lugar una concurrida procesión. La encabeza una estatua del santo ermitaño — casi de tamaño natural- que normalmente se hospeda en la iglesia mayor y que ahora recorre las calles del pueblo al son de marchas y pasodobles. Una vez terminada la procesión, el mayordomo vuelve a convidar a los vecinos a pastas y limonada.

Aunque los actos religiosos acaban aquí, esa misma tarde tiene lugar lo que se conoce como "correr las cintas". Se trata de una carrera popular en la que varios jinetes pasan por debajo de una cuerda que cruza la llamada calle de los Peligros de uno a otro lado. De la cuerda cuelgan varias cintas 


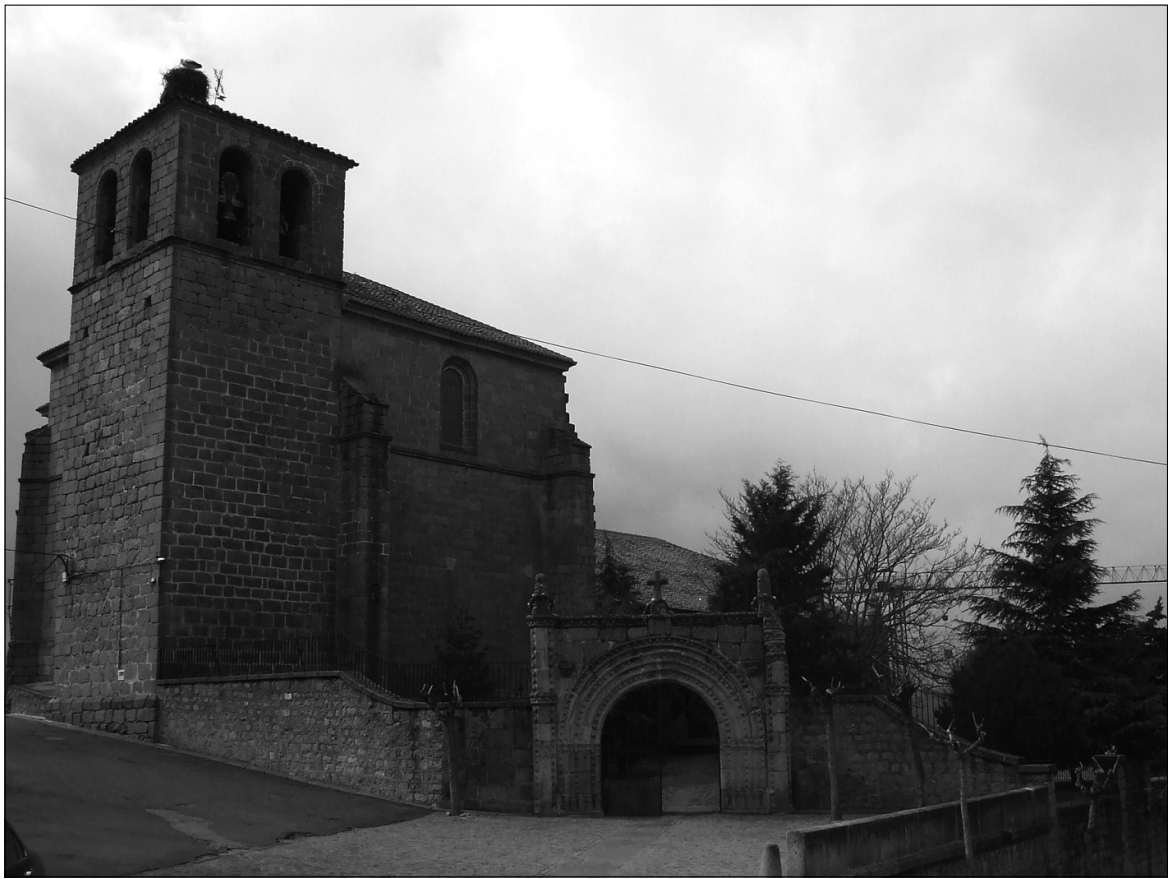

FiguRA 2. San Bartolomé de Pinares. Iglesia parroquial.

de colores con una pequeña arandela. Aquél que, con un objeto punzante, consigue tirar de la arandela en plena carrera desde su caballo, gana un premio. La carrera de las cintas representa, en realidad, un sustituto de las antiguas carrera de gallos en las que dichos animales se colgaban vivos de una cuerda. Al pasar por debajo de ésta, los jinetes trataban de arrancarles la cabeza con la mano, quedándose con ésta como trofeo.

\section{FUEGO RENOVADOR}

Pese a la diversidad de vivencias y enfoques transmitidos por los entrevistados en relación con los actos descritos, el sentimiento unánime es que la fiesta de las luminarias sirve para librar al pueblo de las fuerzas del mal. El fuego y el humo de las hogueras ahuyentan los malos espíritus, proporcionando salud y bienestar tanto a los animales como a sus dueños. Dicha interpretación se corresponde con el lugar que ocupa dicha festividad dentro del calendario agrícola anual. El día 17 de enero se sitúa en pleno período invernal, tradicionalmente caracterizado por el reposo de los trabajos del campo, cuando el labrador abandona el arado, y los animales de labor 


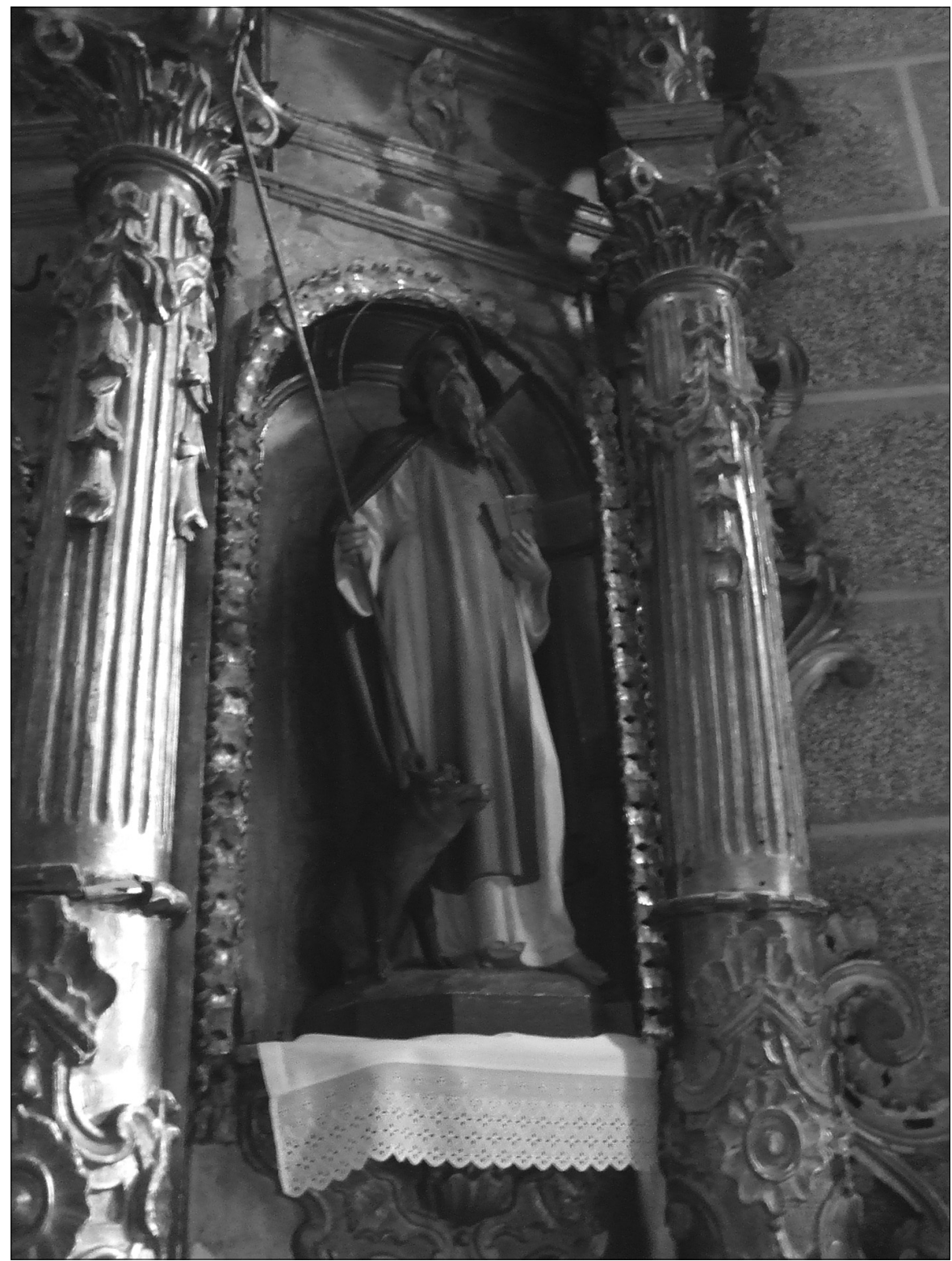

FiguRA 3. San Antonio Abad (Iglesia parroquial de San Bartolomé de Pinares).

pueden asimismo descansar, preparándose para lo que vendrá después. El largo período que precedía la primavera, esto es, el antiguo Año Nuevo en la religión romana arcaica, estaba marcado por ceremonias destinadas a 
purificar a los hombres, los animales y los campos, y a favorecer la renovación del cosmos, así como a rogar que los dioses fueran propicios (Cattabiani 1990: 124-138).

Un ejemplo de dichas ceremonias eran las feriae sementivae (fiestas de la simiente), celebradas en la segunda quincena de enero, para favorecer la fertilidad de los campos y la fecundidad de los animales. En ellas, se lustraban los pueblos mediante ofrendas agrícolas y animales (escanda, mosto, leche, cerdos) a las diosas Ceres y Tierra. Mientras tanto, a las terneras se las adornaba con guirnaldas de flores y se las dejaba reposar. Dicho período era cantado por Ovidio en sus Fastos de forma tan poética como didáctica:

Coronados de guirnaldas, permaneced, novillos, ante los pesebres llenos: vuestra labor retornará con la tibia primavera. Que el aldeano deje suspendido de un poste el arado que ha merecido su descanso: la tierra helada teme cualquier herida producida por él. Y tú, granjero, concluida la sementera, deja descansar a los hombres que la cultivaron. Que la aldea celebre fiesta. Purificad la aldea, campesinos, y ofrendad sobre las hogueras aldeanas los anuales pastelillos. Propíciese a Tellus y a Ceres, madres de las cosechas, mediante la escanda que les es propia y las entrañas de una cerda preñada ${ }^{6}$.

Las fiestas o ceremonias destinadas a la purificación continuaban en febrero (februare en latín significa purificar), siendo éste el mes que marcaba el período de transición que preludiaba el nacimiento de la primavera. En la renovación que tenía lugar durante los meses de enero y febrero, los ritos de expiación dedicados a las almas de los muertos desempeñaban también un papel importante. Hoy en día, el protagonismo de los difuntos ha ido relegándose cada vez más a las festividades en su honor celebradas a comienzos de noviembre. Sin embargo, tanto en la antigua Roma como a lo largo de la Edad Media, la reaparición de los muertos en el mundo de los vivos para contribuir, como simientes, a la renovación cósmica, era patente en muchas ceremonias celebradas a comienzos de cada año (Caro Baroja 1986).

Un modelo claro de cristianización de los ritos de reavivamiento y purificación invernales es la fiesta de la Presentación del Niño Jesús en el Templo, convertida posteriormente en la Purificación de la Virgen. Debía celebrarse el 2 de febrero, ya que la purificación ritual de las madres se producía, según la ley hebrea, a los cuarenta días del nacimiento de las criaturas, momento a partir del cual podían empezar a salir de casa libremente ${ }^{7}$. Di-

${ }^{6}$ Publio Ovidio Nason, Fastos, libro I, 657-696, en Marcos Casquero (1984: 146).

7 Según Agustina Cea Martín, nacida en San Bartolomé de Pinares el 7 de mayo de 1910, "la Virgen salía a Misa con el niño después de cuarenta días de dar a luz, como las mujeres aquí. Hasta que no salían a Misa, no se asomaban ni a la puerta”. 
cha fiesta se conocía también como la Candelaria, porque ese día se bendecían y distribuían entre los fieles candelas o velas, a las que se atribuían virtudes protectoras contra todo tipo de calamidades. Como relata María Gómez González, antiguamente las pequeñas candelas individuales se encendían de un cirio especial que llevaba el sacerdote (al igual que el cirio pascual, símbolo de Cristo, y asimismo, símbolo del fuego nuevo y vital, renovador y fecundador que reaparece cada año en la naturaleza, preparando la primavera). Cada asistente a la ceremonia llevaba un trocito de candela de unos veinte centímetros; éste se cortaba de un rollo de cinco metros que las mujeres solían envolver alrededor de una tabla, formando hiladas transversales, para así ir desenrollando la candela a medida que iba gastándose. Según Gómez González, "las luces venían a simbolizar la presencia espiritual de los muertos", para quienes la Iglesia pedía constantemente la luz eterna ("luzca para ellos, Señor, con tus santos en lo eterno, porque eres piadoso") (Gómez González 2000: 74).

En dicho contexto invernal y renovador es donde se sitúa la festividad de San Antonio Abad, señor del fuego y patrón de los animales, en particular del cerdo (Walter 1996). Sea o no cierto que falleció un 17 de enero, las leyendas y costumbres relacionadas con su fiesta resuenan como un eco de las antiguas lustraciones o ceremonias de purificación, y remiten mucho más al lugar que ocupa en el calendario que a su figura histórica como anacoreta y pastor de almas. Como veremos a continuación, San Antonio Abad fue asumiendo poco a poco las funciones de divinidades paganas anteriores, al tiempo que las recordaba, con lo que muchos ritos precristianos continuaron celebrándose sin apenas variaciones bajo su patrocinio.

\section{LA LEYENDA DE ANTONIO ABAD}

Según la biografía escrita en griego por su discípulo Atanasio de Alejandría a mediados del siglo IV, Antonio había nacido entre 250 y 260 d. C. en el Egipto medio, en el seno de una familia campesina acomodada. A la muerte de sus padres, el joven decidió vender sus propiedades, entregar el dinero a los pobres y retirarse a hacer vida solitaria cerca de su aldea natal, con la intención de dedicarse esencialmente a la escritura y a la oración. No obstante, pronto empezó a experimentar estados psicológicos contradictorios y tentaciones que le causaban un enorme sufrimiento. Según Atanasio, tales estados se le presentaban en forma de espíritus encarnados en todo tipo de figuras monstruosas. Para intentar reconocer su naturaleza específica y, de este modo, poder vencerlos ("buscando una confrontación más directa con los demonios", en palabras de Atanasio), Antonio continuó su retiro progresivo: primero, a un cementerio abandonado, encerrándose en 


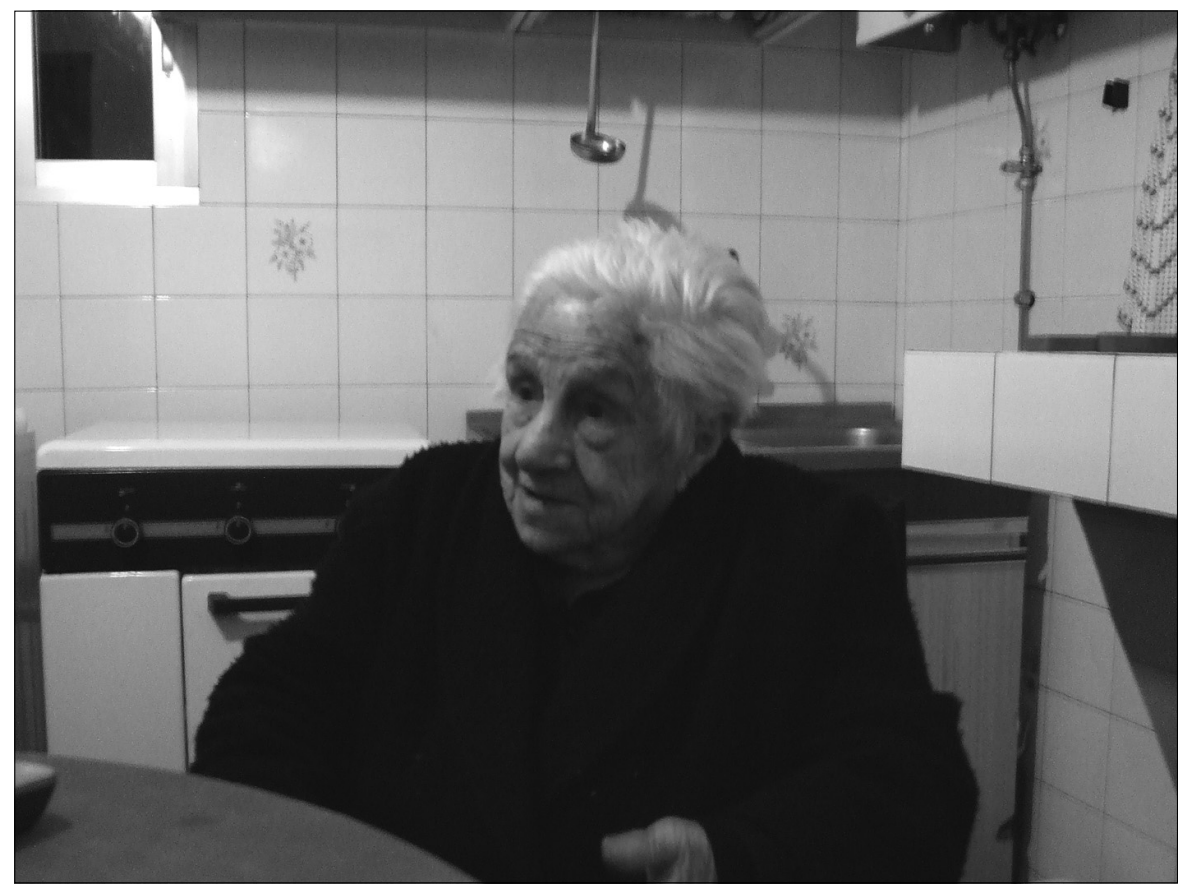

FIguRA 4. Agustina Cea Martín, nacida en San Bartolomé de Pinares el 7 de mayo de 1910

un mausoleo, y, a partir de los treinta y cinco años, al desierto (Atanasio 1992: 8).

La Vita Antonii señala este paso como algo totalmente insólito en la época. Antonio cruza el Nilo y se interna en la montaña, donde ocupa un fortín abandonado. Allí pasa veinte años en absoluta soledad, entregado a la vida ascética. Compadecido ante los ruegos de quienes quieren imitar su vida, abandona durante un tiempo su retiro y se convierte en maestro de monjes o abad (del griego abbâ, que significa padre), formándose en torno suyo una pequeña colonia de ascetas. No obstante, tras unos años de vida comunitaria, Antonio decide huir de la celebridad y se traslada a lo que Atanasio llama la montaña interior o monte Colzim, cerca del mar Rojo (en oposición a la montaña exterior o Pispir, que había sido hasta entonces su residencia y en donde permanece la comunidad de sus discípulos). A pesar de todo, de vez en cuando recibe la visita de sus hermanos e incluso emprende en una ocasión el camino hasta Alejandría para participar en algunos debates contra el arrianismo. Los últimos días de su larga vida (según Atanasio, alcanzó la edad de ciento cinco años) discurren apaciblemente, 
en compañía de dos de sus discípulos, a quienes, llegado el momento de su muerte, suplica que no revelen a nadie el lugar de su sepultura.

Aunque el autor de la Vita afirma explícitamente que Antonio no fue el primer anacoreta, sostiene que sí fue el primero en retirarse al desierto de Egipto, lo que hizo que a partir de entonces empezara a ser considerado como el padre de la vida monacal y, sobre todo, como modelo perfecto de vida solitaria. El desierto había constituido ya desde antiguo un territorio simbólico marcado con el signo de la ambigüedad pues, en medio del vacío casi absoluto, cualquier aparición podía ser señal de la presencia divina, pero también de lo contrario. Más que un lugar de huida, representaba un espacio privilegiado, cuya desnudez lograba sacar a la luz los conflictos interiores de quienes se atrevían a adentrarse en él. De ahí que sea el terreno en que Antonio libra sus batallas contra los espantosos demonios que constantemente le acechan y a quienes, tras prolongados combates, consigue derrotar. A medida que avanza en su progreso espiritual, el peligroso desierto termina convirtiéndose en el lugar de su encuentro personal con Dios, lo que señala la culminación de su vida ascética, basada en la austeridad y en la disciplina (Clark en prensa).

La legendaria Vida de Antonio, al igual que otras muchas hagiografías de los primeros tiempos del cristianismo, establecía un modelo de heroísmo y santidad propuesto a los fieles para ser imitado. El alejamiento de lo real en pos de la ejemplaridad resulta especialmente patente en el caso de Antonio, pues su figura venía a representar al hombre sagrado por excelencia o, como ha llegado a afirmarse, al santo "todavía intersticial [...] cuyo territorio no es tanto el de la diferencia social entre campo y ciudad, como el paisaje imaginario del espíritu" (Cameron 1999: 32-33). La Vida de Antonio no sólo ponía de manifiesto la tensión característica vivida por los primeros cristianos entre el medio rural y el urbano, sino también entre el verdadero y el falso conocimiento, de ahí que se le presente discutiendo temas de teología contra los arrianos (tarea a la que, en realidad, se entregó su biógrafo Atanasio) o tratando de discernir los buenos de los malos espíritus, entre las muchas visiones que constantemente trataban de acosarle (Viller 1937-1995: vol. 3, cols. 1261-91).

Es precisamente esa supuesta habilidad para reconocer $y$, por tanto, dominar a los espíritus o demonios, lo que acabaría por atribuir a San Antonio un señorío especial sobre el mundo infernal y, en particular, sobre el fuego. De ahí la multiplicación de leyendas a lo largo de la Edad Media sobre su función como custodio del infierno, siendo considerado el único santo capaz de engañar a los diablos y, de ese modo, arrebatarles algunas almas que en realidad no se merecerían las llamas eternas. Debido a su estrecha asociación con el fuego, San Antonio era asimismo considerado 
sanador por excelencia del llamado "fuego sagrado" o "fuego de San Antonio", identificado con el herpes zóster y, en general, con cualquier enfermedad de la piel que provocara una sensación de quemazón, lo que terminó asociándose asimismo con el ardor inflamatorio producido por la peste. Su poder para acabar con los incendios tampoco admitía ninguna duda. En una de las muchas biografías del santo todavía escritas en el siglo XVIII se leía que San Antonio Abad,

hace ceniza al fuego sacro, consume al pestifero, siendo particular abogado contra la epidemia perniciosa, por el divino bolcan que continuamente ardia en su pecho, pues no le pudieron apagar las aguas de las adversidades, ni el oceano de las persecuciones. Por cuya razon se ve pintado en muchas casas, y en particular en aquellas que hay hornos y trajinan con fuego, donde en muchos peligros se ha experimentado el divino socorro y grandes maravillas que obra el Hacedor Soberano, por acreditar la santidad de su siervo, apagando voraces incendios de innumerables edificios, valiéndose sus devotos con estampas y retratos, puestos a vista del fuego, milagrosamente quedar atajado, y no passar adelante con su voracidad (Ceballos 1759: 283).

En cuanto al cerdo que habitualmente acompañaba al santo en sus representaciones, según algunas tradiciones se trataba de uno de los diablos vencidos por el ermitaño, y tras ser sometido, obligado a seguirle para siempre. Dicha leyenda suponía una transición capaz de explicar su patronazgo, no sólo sobre el fuego, sino también sobre los animales. Sea como fuere, la introducción del santo de origen oriental en Occidente tuvo lugar en el siglo XI, cuando un noble francés pidió los restos de su cuerpo (que habrían sido trasladados de Alejandría a Constantinopla) al emperador, y los llevó a las tierras que poseía en St. Didier-de-la-Motte, pertenecientes al obispado de Vienne (Navarro 1683: 254-255).

Allí fundó en su honor la orden hospitalaria de los Antonianos, que llevaban como distintivo una Tau o cruz de San Antonio (Sciamanna 2005), cuya principal misión era paliar la peste que azotaba las ciudades y villas, entre otras enfermedades con efectos localizados a lo largo del sistema nervioso que se relacionaban con el llamado fuego sagrado. Se dice que los religiosos de la orden se dedicaban principalmente a la crianza de cerdos que pastaban libremente con una campanilla al cuello, y que eran mantenidos por la caridad pública (Arias Fernández 2006: 13-15). Según la versión de Blas Antonio de Ceballos,

la campanilla pendiente del cuello del animalillo denota la esperanza en el bendito Antonio y su continua proteccion en los comunes males, y la que tiene en su santa mano, ademas de significar vigilancia y despertador de nuestras tibiezas, para que imitemos sus heroycas virtudes, declara la que oyo en el desierto que tenia pendiente al cuello un camello que le traia pan y legumbres de limosna (Navarro 1683: 284). 
Evidentemente, las leyendas en torno a San Antonio Abad o, más comúnmente, San Antón (se decía que el motivo de que se le conociera por un nombre distinto al suyo es que él mismo había dicho "en cierta ocasión por humildad que assi le llamasen" (Navarro 1683: 284), se extendieron y ramificaron a lo largo de los siglos, a medida que crecía su popularidad en todo el área mediterránea. Tal y como escribía Goethe en Roma, durante su Viaje por Italia, el 18 de enero de 1787, esto es, al día siguiente de la festividad celebrada en honor al santo,

San Antonio, abad u obispo, es el patrono de los cuadrúpedos, y su fiesta, una celebración saturnal para estos animales, generalmente tan cargados, así como para quienes los guían y guardan [...] Caballos y mulas, con las crines y las colas entretejidas con vistosas cintas a menudo ostentosas, son conducidos ante una pequeña capilla, algo apartada de la iglesia. Allí, un sacerdote provisto de un gran hisopo salpica con agua bendita [...] a los briosos animales, con el objeto de excitarlos. Cocheros devotos llevan cirios grandes o pequeños, y los señores envían limosnas y regalos a fin de que los valiosos animales no sufran ningún accidente durante todo el año. Los asnos y los animales con cuernos, también de valor y utilidad para sus dueños, toman asimismo parte, modestamente, de esta bendición (Goethe 2001: 178-179).

Las palabras de Goethe todavía resuenan en nuestros oídos al presenciar las fiestas en honor a San Antón que cada año continúan celebrándose en muchas localidades españolas. En medio de una sociedad ya completamente industrializada, han perdurado hasta hoy un buen número de prácticas rituales cuyo origen se remonta a muchos siglos atrás. No obstante, si lo que queremos es tratar de comprender su significado, nuestro objetivo no puede reducirse tan solo a considerarlas bajo el perfil de su arcaísmo, sino más bien a través de las diferentes variaciones en la ejecución de los ritos (Buttitta 1999: 133 y 169). En ese sentido, las informaciones procedentes de quienes, de una manera u otra, siguen participando cada mes de enero en la festividad de las Luminarias de San Bartolomé de Pinares nos brindan una oportunidad única para que tomemos conciencia del sentido original de la fiesta y de cómo ha ido transformándose con el paso del tiempo.

\section{LOS SANTOS ANTONIOS}

Según palabras textuales de Agustina Cea Martín, de noventa y siete años de edad: "San Antón Abad es de nuestra familia" ("mi madre se llamaba Martín Abad, y ellas decían que eran de la familia del santo"). Si bien es cierto que una gran proporción de habitantes de la localidad de San Bartolomé de Pinares se apellidan Abad, como sucede en otros lugares de la geografía española, dicha afirmación adquiere en este contexto un relie- 
ve especial. No hay que olvidar que, hasta hace no mucho tiempo, la devoción por los santos (y en particular por algunos de ellos, como Antonio, considerados "especialistas") (Christian 2000: 31-44) se expresaba mediante un trato familiar, en el marco de una relación contractual, pero no por ello menos apasionada. La noción de que los santos eran abogados personales, familiares y hasta locales llegó a ser muy criticada en la Edad Moderna por algunos protestantes españoles que buscaban relacionarse directamente con Dios, sin recurrir a intermediarios ${ }^{8}$. No obstante, para la mayoría de los creyentes, los santos formaban parte de una tupida red de voluntades celestes que podían propiciarse mediante todo tipo de ofrendas, cuidados e incluso mimos, esperando recibir a cambio los dones deseados.

Según Agustina, San Antón pasaba cada año por encima de las hogueras, pero no únicamente representado en su vara, sino de forma más presencial o, por decirlo de otro modo, más voluntariosa, pues "quería entrar en las lumbres y no le dejaban, pero el santo tenía poder y pasaba por encima, y no se quemaba". Gracias a él, "a los caballos que pasaban las luminarias no les pasaba nada”. Además de velar por la salud de los cuadrúpedos, San Antón, como patrón de los animales en general y del cerdo en particular, era invocado cada vez que uno de ellos enfermaba: "Antes teníamos el cerdo en casa y, si se ponía malo, le pedíamos al santo que lo sanara. Si se ponía bueno, le dábamos al santo como regalo una alforja llena de pies de cerdo"'.

David Moro Gómez ${ }^{10}$, agricultor y tamborilero, de ochenta y cuatro años ("llevo tocando el tambor en las fiestas sesenta y nueve años"), afirma refiriéndose a la época de su juventud: "Entonces había aquí muchos cerdos, y al santo, si no se moría el cerdo, le dábamos el día de la fiesta un patín". Así, pues, a San Antón se le obsequiaba fundamentalmente con donativos (las patas de los cerdos a quienes protegía, de ahí el refrán: "San Antón tiene un guarrito que ni come ni bebe y está gordito"), con el humo de las luminarias ("la lumbre es para ahumar al santo; a San Antón hay que ahumarle"11; "dicen que San Antón se llevaba los malos espíritus, pero había que hacer mucho humo para que librara de los males"12), con música (si-

\footnotetext{
${ }^{8}$ Así, por ejemplo, en 1588, Cipriano de Valera escribía en Los dos tratados del Papa i de la Misa: "Abogado tenemos delante del Padre a Jesu Christo, justo [...] Unos se acojian a un santo o santa, i otros a otro, o a otra, segun su zelo, sin szienzia, i segun su loca devozion. I aun algunas vezes ponian por interzesores aquellos cuyas animas ardian en el infierno" (citado en Christian 2000: 41).

9 Testimonios de Agustina Cea Martín.

${ }^{10}$ Nacido en San Bartolomé de Pinares el 26 de junio de 1923.

${ }^{11}$ Testimonio de David Moro Gómez.

${ }^{12}$ Testimonio de Agustina Cea Martín.
} 


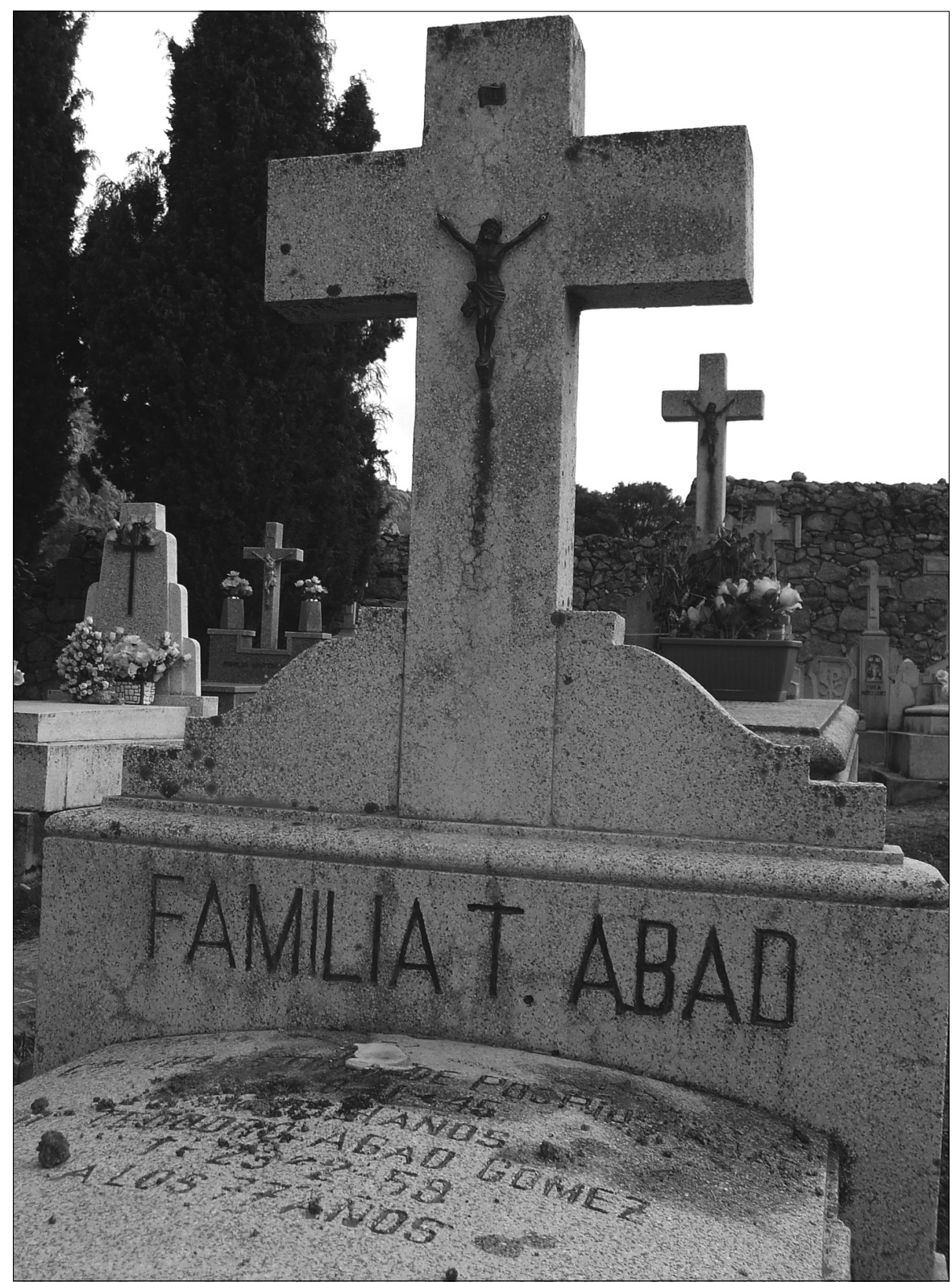

Figura 5. Familia Abad. Para algunos habitantes de la localidad, San Antonio Abad era considerado como un miembro más de su familia, en un sentido literal. 
guiendo un ritmo repetido al son del tambor, que la mayoría tarareaba cantando: "San Antón, ton, torón"), y también con besos ("nevando, salíamos a besar al santo; el del caballo iba helado de frío") ${ }^{13}$.

No obstante, pese a las ofrendas recibidas, el ermitaño Antonio es considerado por la mayoría de los entrevistados un santo pobre, al que constantemente se le relaciona con su homónimo, el franciscano San Antonio de Padua: "A San Antonio le regalaban animales (conejos, corderos, cerdos enteros). ¡A San Antón, pies, na más!"14. El santo "rico", asimismo protector de los animales, cuya festividad se celebra en la localidad cada 13 de junio con una gran subasta pública, comparte atributos con San Antón, lo que crea una cierta confusión, cuando no la asimilación de ambos. De hecho, la bendición de todos los animales del pueblo, y no sólo de los cuadrúpedos, se lleva a cabo en San Bartolomé de Pinares el día de San Antonio de Padua y no el de San Antón, a diferencia de lo que ocurre hoy en día en muchas localidades de la geografía española, incluyendo grandes centros urbanos como Castellón, Málaga, Zaragoza o Madrid. En palabras de Alfredo Martín Abad $^{15}$, teniente alcalde del ayuntamiento y cofundador de una asociación destinada a defender la fiesta de las luminarias,

San Antonio de Padua es el día de los labradores y ganaderos; llevan el ganado a la iglesia y ofrecen un animal al santo; se hace una subasta, y el dinero que se recauda es para la iglesia. Y es que San Antonio de Padua era un santo milagrero: cuando un animal se perdía en el campo, se le rezaba de espaldas a donde se había perdido el animal y, después de rezar la oración al santo, ya no se podía volver a mentar el animal al hablar con nadie, pues había que confiar ciegamente en que el santo lo encontraría.

Según Teodora Sáez García" ${ }^{16}$ cada 13 de junio "se hacía una subasta de animales (ovejas, cabras, gallinas, cerdos, conejos, etc.) que solían volver a comprar los mismos dueños de los animales por mucho dinero. El dinero era para el cura. Se creía que el animal comprado de nuevo transmitía salud al resto del rebaño para todo el año". Alberto Sáez Gordo ${ }^{17}$, explica cómo dentro de la iglesia mayor del pueblo se montaba, y continúa montándose todavía hoy, una telera o redil donde se introducían todos los animales donados: "Donas el mejor ternero y, como tú mismo lo quieres recuperar, al fin y al cabo es una donación de dinero".

\footnotetext{
13 Id.

14 Id.

15 Nacido en San Bartolomé de Pinares el 10 de febrero de 1968.

16 Nacida en San Bartolomé de Pinares el 20 de septiembre de 1947.

17 Nacido en San Bartolomé de Pinares en 1958 y coautor del libro San Bartolomé de Pinares. Memoria y prospectiva (Ávila: Diputación Provincial de Ávila, 1997).
} 
La tendencia a confundir y mezclar los dos santos Antonios ha sido observada por otros estudiosos. Como afirma William Christian (1990: 137), "en España, la devoción a San Antonio de Padua absorbió parcialmente a la de San Antonio Abad, protector de los animales”. Nada más expresivo a este respecto que el santuario de los Santos Antonios de Urquiola (Vizcaya), donde la imagen de San Antonio de Padua tuvo que unirse en el altar mayor a la de San Antonio Abad, debido a la confusión entre las dos ${ }^{18}$. La relación entre ambos santos es también palpable en la ermita de San Antonio de El Tiemblo, localidad perteneciente, al igual que San Bartolomé de Pinares, a la comarca abulense conocida como Tierra de Pinares (Christian 1990: 138).

Según José Luis Alonso Ponga (1981: 3-4), "el motivo de confusión de estos dos santos puede estribar en el hecho de tener el mismo nombre y de que, además, sean los dos afamados milagreros". En efecto, el santo nacido en Lisboa y conocido como Antonio de Padua, cuyo nombre de pila original era Fernando — hasta que él mismo decidió sustituirlo por Antonio al tomar los hábitos, en honor a su admirado Antonio Abad-, adquirió una enorme fama como milagrero y predicador, incluso antes de su muerte, en 1232. Dicha fama se prolongó y aumentó a lo largo de los siglos hasta el punto de que "hoy sigue siendo el santo invocado con más frecuencia en España después de María” (Christian 1990: 132).

La estrecha relación entre ambos santos puede apreciarse asimismo en su iconografía, en particular en el símbolo de la llama de fuego que originalmente había sido atributo exclusivo de Antonio Abad. A partir del siglo XIV, el fuego empezó a aparecer también en manos de Antonio de Padua, a veces bajo la forma de un corazón en llamas, como signo del amor divino que lo inflamaba. En este contexto, y pese a la sorpresa inicial, no resulta del todo extraño comprobar cómo la "vara del santo" mencionada una y otra vez por los informantes de San Bartolomé de Pinares como emblema de la presencia viva de San Antón en su fiesta, la vara que es paseada por las calles del pueblo en la víspera de la festividad y besada con fervor durante la mañana del día 17 de enero por muchos devotos, muestra en realidad la imagen inequívoca de San Antonio de Padua con el niño Jesús en los brazos ${ }^{19}$.

\footnotetext{
${ }^{18}$ Ambas imágenes (de los milagrosos Santos Antonios) presiden el retablo mayor del santuario ("que se halla en una sierra aspera, donde se recojen de ordinario muchos enfermos y pobres y otras muchas personas que padescen de fuego de Sananton, y espiritados, y otras muchas enfermedades") al menos desde el siglo XVII (Vizcarra y Arana 1932: 34-45).

${ }^{19}$ La vara de aluminio utilizada en las dos festividades es la misma y la única diferencia que señala la fiesta de San Antonio Abad es la cinta roja que se añade a la vara
} 


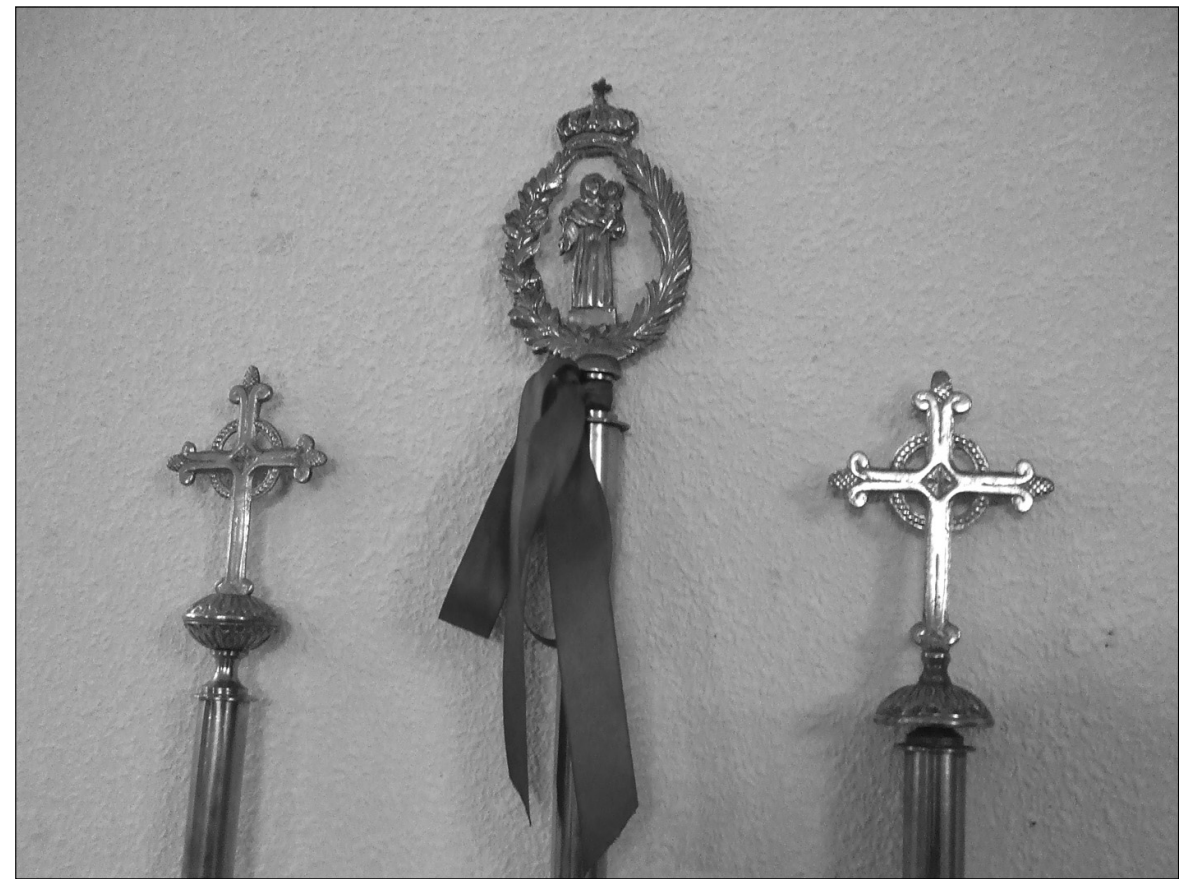

FiguRA 6. La llamada vara del santo que, en realidad, muestra la imagen de San Antonio de Padua con el niño Jesús en los brazos.

\section{FUEGO FESTIVO, HUMO SAGRADO}

Aunque, en principio, las hogueras o luminarias encendidas en la víspera de San Antón representan tan solo un preludio de las ceremonias que tendrán lugar el día siguiente ${ }^{20}$, lo cierto es que el equilibrio antaño existente entre los ritos del fuego y los propiamente religiosos se ha roto definitivamente a favor de los primeros. El protagonismo de las luminarias, cuyo tamaño ha ido aumentando al tiempo que disminuía su número, favorece hoy en día la espectacularidad de la fiesta por encima de otros valores.

labrada con la imagen de San Antonio de Padua. La mayoría de los participantes en ambas fiestas desconocen esta circunstancia. Según María Rosa Gómez Martín (nacida en San Bartolomé de Pinares el 18 de marzo de 1953), "San Antonio de Padua es el santo rico y se la paga él, pues tiene medios. San Antón es el pobre, su cofradía no tiene dinero, y por eso hay una sola vara".

${ }^{20}$ Refiriéndose a Sicilia, Ignazio Buttitta escribe: "Il rito del fuoco è spesso inscrito in un iter ceremoniale del quale il momento dell'accensione è solo un elemento, nella gran parte dei casi, connotabile come preludio di cerimonie più marcatamente religiose (processioni di reliquie, di simulacri, atti penitenziali, etc.)" (Buttita 1999: 136). 
Antiguamente, cada familia prendía una pequeña lumbre junto a la puerta de su casa, mientras que hoy es el ayuntamiento el encargado de encender varias hogueras que, según Alfredo Martín Abad, "son siete veces más grandes que antes". De acuerdo con David Moro Gómez, "antes las hogueras eran pequeñas, y en cada puerta había una. Ahora es una exageración: preparan unas hogueras que dan miedo". Según Encarnación Gastelut Vá1llo ${ }^{21}$, "antes eran mucho más bajas; ahora no son hogueras, son exageraciones". María Martín Mayorga ${ }^{22}$, de noventa y un años, insiste a su vez en que "ya no es como antes, cuando se ponía luminaria como es debido; ahora no sé cómo no arde el pueblo". Según Teodora Abad de Propios ${ }^{23}$, la explicación es clara: "Con esas hogueras tan grandes, y nunca ha habido un fuego en el pueblo: ¡milagro de San Antón bendito!”.

El progresivo gigantismo de las hogueras implica que la recogida de ramos haya pasado de ser una tarea encomendada principalmente a los niños y adolescentes ${ }^{24}$ a convertirse en una campaña organizada por los adultos, en su mayoría varones, con vistas a conseguir la máxima cantidad de leña en el menor tiempo posible. Según Alfredo Martín Abad, "antes eran dos cargas de ramos en cada puerta”. Y en palabras de Agustina Cea Martín, "yo iba de pequeña a por un hacecillo; nos lo ataban a la espalda con una cuerda: era una cosa pequeña porque no podíamos con más". Según Encarnación Gastelut Vaíllo: "Ahora hacen unas lumbres exageradas. Antes, a los niños de la escuela nos daban permiso dos o tres días para que fuéramos a por ramos y hacecillos". De acuerdo con David Moro Gómez, "ahora traen dos camiones: una exageración” y, según Vicente Herrero Cea ${ }^{25}$, "antes la fiesta era más sana, más natural y familiar. Ahora es una exhibición: a ver quién da más. Se iba a por ramos para hacer la lumbre y con poco se conformaba la gente. Ahora es exagerado la lumbre que ponen: dos camiones".

Frente a la atención prestada hoy en día a los saltos espectaculares de los jinetes a través de las hogueras, que han pasado a ser el centro indudable de la fiesta, antiguamente "algunos caballos saltaban, y otros no" ${ }^{26}$. Lo importante para los animales, más que el hecho de cruzar la hoguera, era

${ }^{21}$ Nacida en San Bartolomé de Pinares el 25 de marzo de 1923.

22 Nacida en San Bartolomé de Pinares el 25 de agosto de 1916.

23 Nacida en San Bartolomé de Pinares el 15 de septiembre de 1935.

${ }^{24}$ Como afirma Ignazio Buttitta para Sicilia, "il momento della raccolta, così come l'attuazione della sequenza rituale, possono essere, di volta in volta, iniziativa pubblica o privata [...] e procedere in maniera spontanea o organizzata [...] In buona parte si tratta di bambini e ragazzini, non di rado riuniti in bande di quartiere" (Buttitta 1999: 140).

25 Nacido en San Bartolomé de Pinares el 20 de mayo de 1949.

26 Testimonio de María Martín Mayorga. 


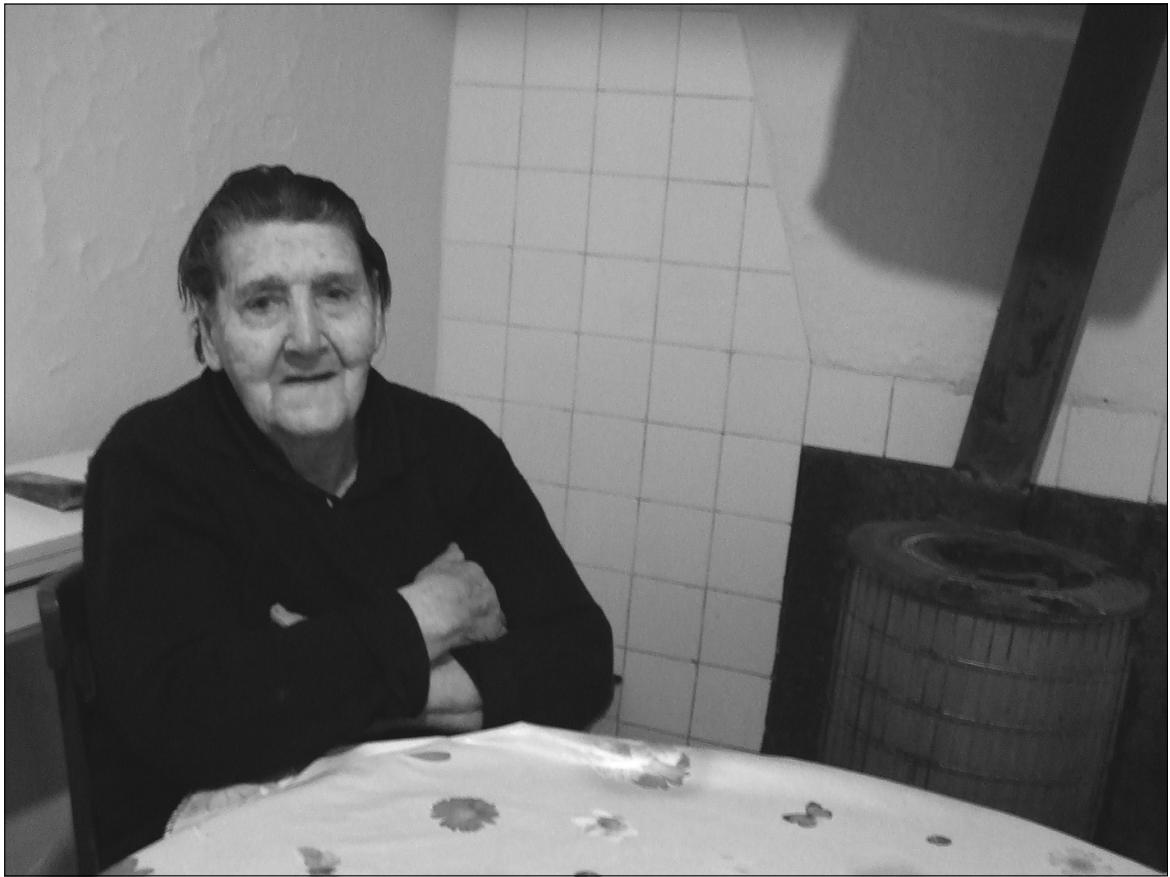

Figura 7. María Martín Mayorga, nacida en San Bartolomé de Pinares el 25 de agosto de 1916

impregnarse del humo purificador que despedían las luminarias, con lo que la circunvalación ritual en torno a las mismas se consideraba suficiente (Buttitta 2002: 95). No obstante, ya desde muy antiguo, los saltos por encima y a través de las hogueras representaban para los jinetes que se atrevían a desafiar el peligro del fuego un rito de paso, una prueba iniciática mediante la cual los jóvenes varones tenían ocasión de mostrar su valor y destreza (Van Gennep 1986; Dumézil 1929). Según varios informantes, "antes sólo saltaban hombres, no mujeres ni niños".

Evidentemente, estos y otros cambios se deben en gran medida a las transformaciones económicas que en los últimos cuarenta años han borrado el sistema de vida que caracterizó a la población de San Bartolomé de Pinares durante muchos siglos. Las primeras noticias acerca de la localidad se remontan al siglo XIII, cuando la aldea, "un concejo aislado entre las montañas abulenses y desconocido casi por todos” (Ser Quijano 1987: 15), constituía "un lugar esquivo, e que eran muy pobles y menguados"27. Las

${ }^{27}$ Dicha frase pertenece a la descripción de la aldea por unos caballeros de Ávila en la visita realizada en 1274 con motivo de la concesión de una herencia. El primer docu- 
condiciones de vida siguieron siendo durísimas durante mucho tiempo, a pesar de que en el siglo Xvi la primitiva aldea experimentó un proceso de desarrollo que la situó entre los núcleos más influyentes de Tierra de Pinares $^{28}$. Sea como sea, la economía del pueblo hasta la década de los setenta, cuando se experimentó un boom de la construcción, se basada principalmente en la explotación de la madera y del ganado (aunque se labraba la tierra, el suelo era considerado "estéril y miserable") (Martín Peñas y otros 1997: 114). Hasta entonces, la decisiva importancia de los animales de labor estaba en estrecha conexión con la devoción a los Santos Antonios, así como con el rito de purificación de las cabalgaduras que cada año se hacía coincidir con la festividad de San Antón Abad.

$\mathrm{Al}$ ir desapareciendo la dependencia con respecto a las cabalgaduras, así como la intimidad de los dueños con sus animales (burros, mulas, caballos), la fiesta en honor a San Antón fue decayendo en muchas otras localidades en las que se produjo una evolución semejante. Sin embargo, la creciente afición por la equitación que se ha producido en San Bartolomé de Pinares en los últimos años ha desempeñado un papel decisivo para revitalizar la fiesta, aunque los presupuestos de la misma hayan cambiado notablemente. Según Teodora Abad de Propios, "antes había muchos burros, muchísimos, y este año sólo pasaron dos". Y, de acuerdo con los datos transmitidos por Alfredo Martín Abad, "hace algunos años solía haber treinta o cuarenta caballos y unos quince burros; este año han pasado ciento veinte caballos y cuatro burros". Según palabras de Teodora: "Antes se pasaban las luminarias por devoción al santo; ahora, para exhibir a los caballos. Antes eran pencos, caballos de labranza; ahora son caballos de capricho". Encarnación Gastelut Vaíllo los denomina "caballos de presumir". Según Vicente Herrero Cea, "ahora se trata de ver quién tiene el caballo mejor y más bonito. Mucha gente viene de fuera a exhibirse".

mento donde aparece citado el lugar como "Sant Bartholome" y situado "in pinares" es de 1250. San Bartolomé era entonces una de las setenta y tres aldeas pertenecientes al sexmo de Santiago, uno de los siete distritos rurales dependientes de las parroquias que componían la Universidad y Tierra de Ávila (Ser Quijano 1987: 19).

${ }^{28}$ En este sentido, resulta significativo el documento por el cual el rey Felipe II se dirigía al concejo de San Bartolomé, consciente de los apuros y dificultades padecidos por sus habitantes: "Don Felipe II, por la gracia de Dios Rey de Castilla y León [...], por cuanto de parte de vos, alcaldes y Regimiento del Concejo de San Bartolomé de Pinares, jurisdicción de la ciudad de Ávila, nos fue hecha relación diciendo que desde la dicha ciudad de Ávila había más de cuatro leguas de camino, y en él un gran puerto y dos ríos, a cuya causa todo el invierno padecíades mucho trabajo por las nieves, fortuna y grandes avenidas de dichos ríos". (Archivo Municipal, Escrituras, provisiones y ejecutorias a favor del Concejo. Deslindes. 1574) (citado en Martín Peñas y otros 1997: 31). 
Entre las polémicas actuales en torno a la fiesta y su evolución, destaca la que mantienen quienes desearían trasladarla al fin de semana y quienes prefieren que se mantenga el día de San Antón. Los partidarios del cambio de fecha, por lo general nacidos en el pueblo pero actualmente emigrados a la ciudad, expresan su deseo de poder acudir a la fiesta con más facilidad desde sus lugares de trabajo y residencia. Otros simplemente aducen motivos económicos y de prestigio, destacando el aumento en la capacidad de convocatoria que tendría la fiesta si se celebrara en sábado y domingo. Según confesión espontánea de Alejandro Mayoral Badillo29: "Esto de las Luminarias, no San Antón, habría que hacerlas en fin de semana. Que luego la cosa religiosa, San Antón y todas esas cosas, que la hagan el día que corresponde". Y en palabras de su esposa, Teodora Sáez García ${ }^{30}$ : "Es que haciéndolo el fin de semana viene mucha más gente. Este año, que cayó en jueves, sólo hubo dos mil. Otros años ha habido cuatro mil personas". A lo que añade Alejandro: "Pues cuanta más gente venga, más dinero dejan, se dará más auge a estas fiestas y se hablará más de ellas. El que tiene una carnicería hace negocio, los bares, los hostales, etc.".

A la pregunta de si preferirían que la fiesta se trasladase a fin de semana, los más longevos responden contundentemente que no. Agustina Cea Martín, que a sus casi noventa y ocho años se autodefine como centenaria, da en la clave del asunto con pocas palabras: "Yo digo que la fiesta en su día. En eso soy acérrima. Pero como las fiestas ahora son para las personas y no para los santos...”. Encarnación Gastelut Vaíllo exclama abiertamente: "Yo digo que el día es el día. El cumpleaños, que lo celebre cada uno cuando quiera, pero la fiesta, cuando es general, no". María Martín Mayorga insiste asimismo en mantener la festividad el día de San Antón, al tiempo que establece una relación entre los dos santos Antonios: "La fiesta está bien el día suyo. La fiesta es la fiesta. San Antonio también lo quieren cambiar, pero ha sido siempre el trece de junio. Yo un año mandé un cordero; otro, un gallo...". Según información de Alfredo Martín Abad, "hace veinte años se hizo un referéndum sobre el tema, y la mayoría quiso mantener la fiesta en su día". No obstante, todas las tendencias apuntan a que en el futuro, como ha venido ocurriendo en otras localidades, la fiesta se desplace, quizá no sólo a fin de semana, sino incluso a otra estación del año, dada su pérdida de vinculación con los procesos productivos tradicionales y con el calendario festivo cristiano.

Una de las transformaciones recientes de la fiesta más señalada por los entrevistados es el hecho de que, desde el año 2000, haya dejado de ser

\footnotetext{
${ }^{29}$ Nacido en Ávila el 9 de febrero de 1946.

${ }^{30}$ Nacida en San Bartolomé de Pinares el 20 de septiembre de 1947.
} 
organizada (y financiada) por el mayordomo y sus dos ayudantes o jurados. Antiguamente, el cargo de mayordomo (del latín, maior y domus; esto es, el principal encargado de administrar la casa o, en este caso, la localidad, en tanto que comunidad) era muy solicitado. Según David Moro Gómez, "antes se juntaban tres personas, tres amigos, y cada año era mayordomo uno; ahora hacen de mayordomo, ya no hay mayordomo de verdad". Según Victoria Hernández de Propios, se trata de un "mayordomo postizo"31. Actualmente, es el Ayuntamiento el que se hace cargo no sólo de la organización, sino también de los gastos de la fiesta, que han ido en aumento, disparándose en los últimos años, en contraste con la austeridad predominante durante mucho tiempo: "Antes el convite era sencillo: vino, alguna galleta"32; "en aquellos años, nadie asaba chuletas: no había dinero"33. Según María Martín Mayorga, "ahora ya no hay quien sea mayordomo, pues sale muy caro".

El motivo de la desaparición del cargo como tal no es, sin embargo, estrictamente económico, sino más bien religioso, ya que ser mayordomo constituía una ofrenda o voto a San Antón, en cumplimiento de una promesa, como agradecimiento por ciertas gracias recibidas, cuando no una petición al santo que sería recompensada con posterioridad. Según Encarnación Gastelut Vaíllo,

se era mayordomo por ofrenda o petición al santo; ahora van porque quieren, pero ya no es lo mismo, van como mandaos. Antes se ofrecía uno al santo: le ofrecías la pata del cerdo al santo si se había salvado, como agradecimiento. Otros ofrecían una vela; otros, una misa; otros, ser mayordomo. Hacíamos cola para ser mayordomos; ahora ya no hay quien lo haga y se ha hecho cargo el Ayuntamiento, pero ya no es lo mismo.

Según Agustina Cea Martín, "cada año pedía serlo uno, y tenían que esperar a que les tocara el turno, porque había muchos".

En teoría, la financiación de la fiesta era incumbencia no sólo del mayordomo, sino de toda la comunidad, a través de los donativos ofrecidos al santo por sus devotos. En la práctica, la cantidad recogida (a menudo en especie, en forma de patas de cerdo) no era suficiente, aunque sí se mantenía el sentido colectivo y democrático de la celebración. Ello enlazaría con antiguas tradiciones (que en algunas localidades sicilianas se mantuvieron hasta los años treinta del siglo xx) por las que uno o varios cerdos se dejaban sueltos por las calles para ser alimentados por los vecinos o, como

\footnotetext{
31 Nacida el 23 de diciembre de 1955.

32 Testimonio de Agustina Cea Martín.

33 Testimonio de Teodora Abad de Propios.
} 
acostumbraba a decirse, por la llamada "caridad pública". Dichos cerdos eran considerados sagrados y nadie se atrevía a tocarlos, ya que hacerlo se interpretaba como una profanación contra el santo. La víspera de San Antón se sacrificaban, la carne era comprada por los fieles y el dinero recaudado servía para financiar los festejos (Buttitta 1999: 25).

Actualmente, el festín celebrado la víspera de San Antón en torno a las hogueras es cada vez más copioso. Sin embargo, el hecho de consumir víveres en enormes cantidades ya no tiene el sentido que se asociaba a la abundancia alimentaria en otras épocas, cuando el despilfarro constituía una forma de derroche sacrificial, un exorcismo contra la escasez y la inseguridad cotidianas (Buttitta 1999: 148-149). Antiguamente, cuando las hogueras eran más numerosas y menos altas, la cena familiar y vecinal sobre las brasas entrañaba un sacramento de comunión hasta cierto punto íntimo: hoy en día, el banquete con el que concluyen los saltos espectaculares de los jinetes sobre las luminarias representa más bien un rito socializador en buena medida enfocado hacia el exterior. Por un lado, el festín refuerza los vínculos entre los nativos y habitantes de la localidad; por otro, supone una forma de prestigio y ostentación de cara a los forasteros, cuyo número aumenta cada año. Según Marino Gastelut Vaíllo ${ }^{34}$, "antes la fiesta era familiar, más natural; ahora viene mucho personal de fuera".

Son muchos los factores que han determinado la evolución de la fiesta en los últimos años, pero entre ellos destaca, sin duda, el hecho de que en el año 2003 se convirtiera en el eje de un intenso debate entre militantes ecologistas y grupos de vecinos de San Bartolomé de Pinares. Todo comenzó cuando, a finales de enero, la Asociación Nacional para la Protección y el Bienestar de los Animales (ANPBA) denunció la fiesta de las Luminarias ante la Junta de Castilla y León, debido a los "tratos abusivos" sufridos por los caballos participantes. Según los denunciantes, atravesar las hogueras provocaba en los equinos "angustia y estrés", ya que estos animales tienen una "aversión natural" al fuego, lo que se demuestra por la tensión y la rigidez con que lo cruzan y por los "intensos resoplidos" que emiten. La noticia llenó de indignación a buena parte de los vecinos del pueblo y, como respuesta, un grupo de éstos, en su mayoría jóvenes jinetes, crearon la Asociación en Defensa de las Luminarias y Amigos del Caballo (ADELUACA) ${ }^{35}$.

En noviembre del mismo año, la Junta de Castilla y León prohibió que los caballos atravesaran las hogueras y encomendó la labor de control al ayuntamiento de la localidad. La administración regional solicitó entonces que

\footnotetext{
${ }^{34}$ Nacido en San Bartolomé de Pinares el 3 de marzo de 1933.

${ }^{35}$ La página web de la asociación es: http://www.lasluminarias.com. La fotografía está tomada de aquí.
} 
"se recuperase la antigua tradición, según la cual los caballos atravesaban las humaredas de las fogatas extinguidas como rito de purificación”, y no las llamas. Además, anunciaron su oposición a que las luminarias pudieran ser declaradas fiesta de interés turístico regional, como solicitaba el ayuntamiento. Mientras tanto, la Junta de Castilla y León seguía utilizando como atractivo turístico la imagen de un caballo en pleno salto, atravesando una espectacular hoguera. Pese a la mencionada prohibición y a la presencia vigilante de la guardia civil en la fiesta a partir de aquel momento (en realidad, los guardias ni siquiera entraban en el centro del pueblo, sino que se quedaban

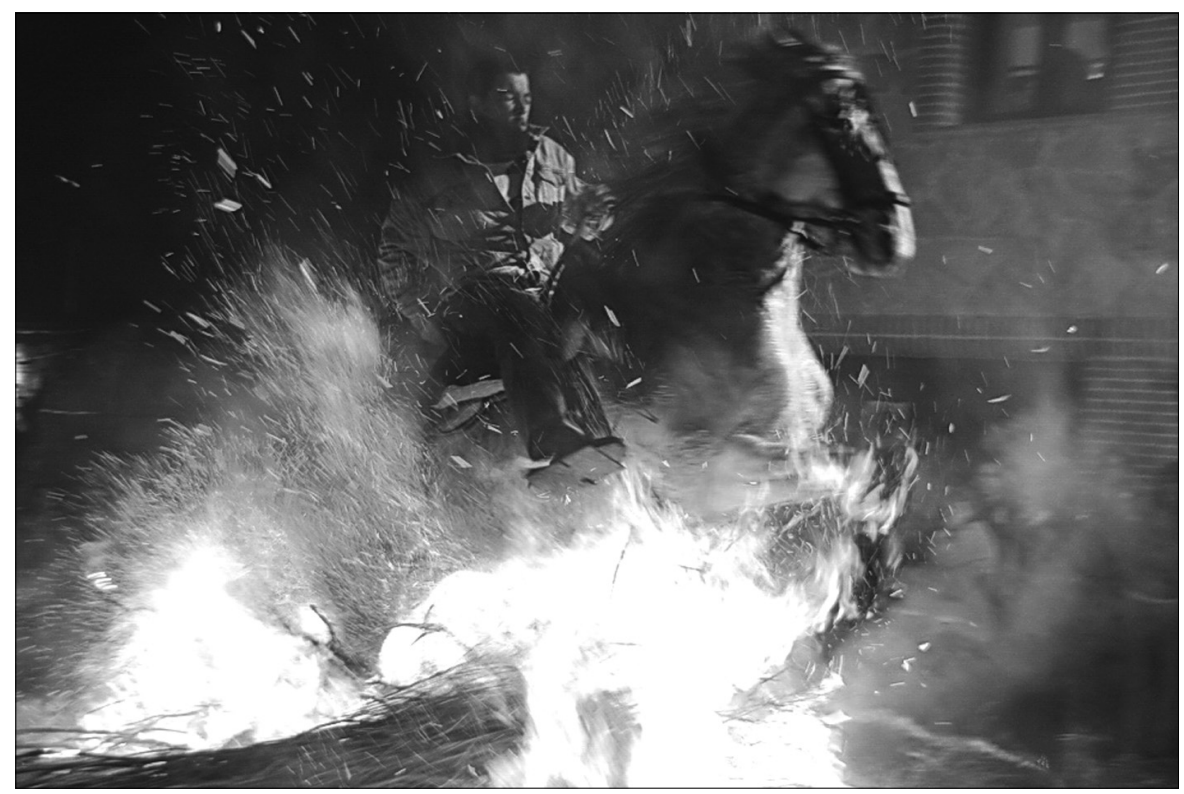

FIgURA 8. Saltos a caballo por encima de las hogueras o luminarias.

apartados a las afueras), los caballos siguieron saltando las luminarias. Ello provocó nuevas denuncias por parte de la asociación ecologista, además de un cambio de actitud de la guardia civil, cuyos agentes se colocaron junto a las hogueras para tratar de impedir que los caballos cruzaran las llamas, medida que no alcanzó éxito alguno (García Robledo 2005: 6-11).

Según Alfredo Martín Abad, cofundador y presidente actual de ADELUACA,

hubo muchas denuncias contra determinados jinetes, y las multas eran de mil quinientos euros por persona, pero la Junta de Castilla y León las desestimó apoyándose en el informe de un veterinario según el cual los caballos no sufrían daño 
alguno. En 2005 los ecologistas volvieron a la carga con otra acusación, esta vez contra la Junta de Castilla y León, por haber desestimado las denuncias anteriores. Pero la Junta de Castilla y León ha paralizado el caso.

Lo cierto es que, con el apoyo activo de muchos jinetes y entusiastas defensores de la fiesta — sin olvidar la aceptación implícita de la minoría más longeva que, pese a reconocer la potencial peligrosidad de las actuales hogueras, se sitúa solidariamente del lado de las generaciones jóvenes-, la fiesta de las luminarias ha continuado celebrándose hasta hoy, con una fama creciente. No sólo no se han limitado los saltos de los caballos a través del fuego, sino que, por el contrario, la participación y la exhibición de los jinetes ha ido en aumento, junto con la afluencia de visitantes y la propaganda en los medios de comunicación, centrada precisamente en la espectacularidad de los saltos.

La ambigüedad de las palabras de Encarnación Gastelut Vaíllo respecto a la controversia de los últimos años resulta significativa por sí misma: "Siempre se han saltado las hogueras. Ahora vienen los verdes y los coloraos y dicen lo que quieren. Eso sí, eran mucho más bajas: ahora no son hogueras, son exageraciones". Hasta los más acérrimos partidarios de la fiesta en su estado actual incurren en contradicciones:

Yo no estoy de acuerdo con la sociedad protectora de animales, pues dicen que los caballos cogen estrés y la verdad es que los están mimando. Una vez un caballo se cayó en medio de una hoguera y al momento la gente se tiró a la hoguera y se sacó al caballo ileso, y no tardó nada el caballo en salir. Arropan a los caballos con mantas después de la fiesta para que no se les enfríe el sudor, pues han sudado mucho saltando la hoguera ${ }^{36}$.

La naturaleza ambivalente del fuego, a un tiempo creador y destructor, vuelve a representarse cada año en la fiesta de las luminarias como homenaje al ermitaño que, según la leyenda, fue capaz de dominar el poder abrasivo de las llamas tras aprender a controlar sus propias pasiones. Hoy en día son cada vez menos quienes relacionan su vivencia personal de la fiesta con la figura del santo a la que desde hace siglos ha venido consagrándose. Sin duda, los valores de la religiosidad tradicional han cedido paso a otros nuevos, no menos importantes para quienes en los últimos años han decidido defender, mantener y fomentar su fiesta en San Bartolomé de Pinares contra toda fuerza en contrario.

Al margen de las polémicas sobre el significado último del fuego festivo, asociado por algunos estudiosos a arcaicos cultos de origen solar y, en opinión de otros, a antiguas ceremonias de purificación mediante el humo (Buttitta 1999: 131-139), resulta indiscutible la vigencia y la popularidad cre-

\footnotetext{
${ }^{36}$ Testimonio de Alejandro Mayoral Badillo.
} 
ciente de los ritos ígneos celebrados a lo largo de toda la geografía peninsular. Más allá de la función instrumental de las hogueras como emisoras de luz y calor, o como implacables aniquiladoras de lo negativo y desechable, la fiesta de las luminarias de San Antón subraya año tras año la magnitud expresiva tanto del fuego como del humo: dos poderosos vehículos de comunicación entre lo lúdico y lo trascendente. Según Vicente Herrero Cea, "el día de la fiesta, el humo huele a monte, a pino y romero, y se mete en las casas hasta el fondo". Y en palabras de Encarnación Gastelut Vaíllo, "no se ve nada, no puedes andar, ni ir por la calle", pero a pesar de todo "hace falta dar humo al santo y cuanto más humo le damos, más contentos estamos".

\section{BiBLIOGRAFÍA CITADA}

Alonso Ponga, J. L. 1981. "Manifestaciones populares en torno a San Antón en algunas zonas de Castilla y León”. Revista de Folklore 2: 3-10.

Anta Félez, J. L. 1997. "Las lumbres de san Antón en Jaén. Hibridación cultural y contexto urbano", en V. Sánchez Ramos y J. Ruiz Fernández (eds.), Actas de las Primeras Jornadas de Religiosidad Popular. 381-391. Almería: Instituto de Estudios Almerienses.

Arias Fernández, A. 2006. "San Antonio Abad y el hospital de beneficencia de León (I y II)". Argutorio, 16 y 17: 13-15 y 9-12.

Atanasio de Alejandría.1992. Vida de San Antonio, padre de los monjes. Sevilla: Apostolado Mariano.

Bayard, J.-P. 1973. La symbolique du feu. París: Payot.

Buendía López, J. L. 1987. "San Antón y la fiesta del fuego", Crónica de la cena jocosa. Asociación de amigos de San Antón: 49.

Buttitta, I. E. 1999. Le fiamme dei santi. Usi rituali del fuoco in Sicilia. Roma: Meltemi.

Buttitta, I. E. 2002a. Il fuoco. Simbolismo e pratiche rituali. Palermo: Sellerio.

Buttitta, I. E. 2002b. La memoria lunga. Simboli e riti della religiosità tradizionale. Roma: Meltemi.

Cameron, A. 1999. "On defining the Holy Man", en J. Howard-Johnston y P. Antony Hayward (eds.), The Cult of Saints in Late Antiquity and the Middle Ages. Essays on the Contribution of Peter Brown: 27-43. Oxford: Oxford University Press.

Caro Baroja, J. 1986. El Carnaval (análisis histórico-cultural). Madrid: Taurus.

Castellanos de, S. B. 1848. "Costumbres españolas: De la romería titulada las vueltas de San Antón". Museo de las Familias 6: 19-20.

Cattabiani, A. 1990. Calendario. Las fiestas, los mitos, las leyendas y los ritos del año. Barcelona: Ultramar. $1^{\underline{a}}$ ed. en italiano 1988.

Ceballos de, B. A. 1759 [1719]. Flores de el yermo, pasmo de Egypto, assombro de el mundo, sol de el Occidente, portento de la gracia. Vida y milagros de el grande San Antonio Abad. Barcelona: María Ángela Martí.

Christian, W. A., Jr. 1990. Apariciones en Castilla y Cataluña (siglos XIV-XVI). Madrid: Nerea. $1^{\underline{a}}$ ed. en inglés 1981.

Christian, W. A., Jr. 2000. "Mediazione celeste in Spagna nell'età moderna", en G. Fiume (ed.), Il santo patrono e la città. San Benedetto il Moro: culti, devozioni, strategia di età moderna. Venezia: Marsilio.

Clark, S. (en prensa). "St Anthony and his demons: the art of discernment". 
Cruces Villalobos, F. 1994. "Símbolos en la ciudad: la caravana de animales". Revista de Dialectología y Tradiciones Populares 49: 49-70.

Dumézil, G. 1929. Le problème des centaures. Étude de mythologie comparée indoeuropéenne. París: Annales du Musée Guimet.

García Robledo, P. 2005. "La danza del caballo y el fuego". Ávila Digital 20: 6-11.

García Rodero, C. 1992. España, fiestas y ritos. Barcelona: Lunberg.

Goethe, J. W. 2001 [1898]. Viaje a Italia. Barcelona: Ediciones B.

Gómez González, M. 2000. Crónicas de mi pueblo. Madrid: Edición Personal.

González Alcantud, J. A. y M. J. Buxó Rey (eds.). 1997. El fuego: mitos, ritos y realidades. Barcelona: Anthropos.

Elías Pastor, L. V. 1985. "La fiesta de San Antón en La Rioja". Revista de Folklore 60: 183189.

Fernán Chamón, A. L. 1983. "La fiesta de San Antonio Abad en Navalvillar de Pela". Narria 25-26: 42-47.

Hoyos, N. de 1957. Las fiestas de San Antón. Madrid: Publicaciones Españolas.

Lera de Isla, A. 1982. "Del folklore campesino: la fiesta de San Antón". Revista de Folklore 13: 20-22.

Luis, M. T. de 1993. Enciclopedia de las fiestas de España. Madrid: Información y Prensa. Marcos Casquero, M. A. (ed.). 1984. Publio Ovidio Nason. Fastos. Madrid: Editora Nacional. Martín Peñas, D.; A. Sáez Gordo y F. J. Luis Jiménez. 1997. San Bartolomé de Pinares. Memoria y prospectiva. Ávila: Diputación Provincial de Ávila.

Martínez González, M. 1980. "La 'sanantonada' de Mirambel. Introducción a su estudio". Teruel: Revista del Instituto de Estudios Turolenses 63: 55-88.

Navarro, J. 1683. Vida y milagros del principe de los anacoretas y padre de los cenobiarcas, nuestro padre San Antonio Abad, el Magno. Barcelona: Serra y Martí.

Rúa Aller, F. J. 2009. "Costumbres leonesas en torno a San Antón y el fuego". Revista de Folklore 338: 66-72.

Sánchez Gómez, M. A. 1995. El bien y el mal en la tradición festiva española. Salamanca: Centro de Cultura Tradicional.

Sciamanna, E. 2005. The Tau. The Origins and Franciscan Tradition of the Symbol. Assisi: Minerva.

Ser Quijano, G. del 1987. Documentación medieval del Archivo Municipal de San Bartolomé de Pinares (Ávila). Ávila: Gran Duque de Alba.

Van Gennep, A. 1986 [1919]. Los ritos de paso. Madrid: Taurus.

Velasco Má́llo, H. M. 2009. "Naturaleza y cultura en los rituales de San Antonio". Revista de Dialectología y Tradiciones Populares LXIV (1): 237-246.

Viller, M. y otros (eds.). 1937-1995. Dictionnaire de Spiritualitè Ascétique et Mystique. Doctrine et Histoire. París: Beauchesne.

Vizcarra y Arana, B. 1932. Reseña histórica del multisecular santuario de los Santos Antonios de Urquiola. Vitoria: Montepío Diocesano.

Walter, Ph. (ed.). 1996. Saint Antoine, entre mythe et légende. Grenoble: Université Stendhal.

Fecha de recepción: 20 de julio de 2009

Fecha de aceptación: 7 de marzo de 2011 